\section{AL-AZHAR Dental Journal}

F $\quad \mathrm{o} \quad \mathrm{r}$

$\mathrm{G} \quad \mathrm{i} \quad \mathrm{r}$
The Official Publication of The Faculty of Dental

Medicine For Girls,

Al-Azhar University Cairo, Egypt.

Print ISSN 2537-0308 • Online ISSN 2537-0316

ADJ-for Girls, Vol. 7, No. 3, July (2020) - PP. 361:367

\title{
Effect of Different Anticollagenolytic Agents on Dentin Erosion before and After Casein Phospho Peptides-Amorphous Calcium Fluoride Phosphate Application
}

\author{
Nourhan M. Moustafa ${ }^{1^{*}}$, Maha A. Niazy², Essam A. Naguib ${ }^{3}$, Rasha H. Afifi ${ }^{4}$
}

Codex : 45/20.07

azhardentj@azhar.edu.eg

http://adjg.journals.ekb.eg

DOI: $10.21608 /$ adjg.2020.14217.1186

Restorative Dentistry

(Removable Prosthodontics, Fixed

Prosthodontics, Endodontics, Dental

Biomaterials, Operative Dentistry)

\section{KEYWORDS}

Aloe vera, Chlorhexidine,

Erosion, Microhardness

\begin{abstract}
Purpose: This study aimed to compare the effect of two anticollagenolytic agents, chlorohexidine and Aloe vera on dentin microhardness and their effect as pretreatments on the remineralization potential of CPP-ACFP. Materials and Methods: For this study, 40 extracted sound human premolars were subjected to artificial erosion and randomly divided to two equal groups (20 premolars each) according to immersion in the tested anticollagenolytic agents $(A)$; group $\left(A_{1}\right)$ Aloe vera and group $\left(A_{2}\right)$ Chlorhexidine. Each group was further subdivided into two equal subgroups (10 premolars each) according to microhardness measurement $(\mathrm{B})$; group $\left(\mathrm{B}_{1}\right)$ : before CPP-ACFP application and group $\left(\mathrm{B}_{2}\right)$ : after CPP-ACFP application. Results: Results showed no statistically significant difference between Aloe-Vera and CHX; both statistically increased dentin microhardness. After immersion, AFCP showed statistically significantly higher mean microhardness than no AFCP application $(\mathrm{P}$-value $=0.003)$ for Aloe vera and $(\mathrm{P}$-value $=0.012$ ) for CHX. Conclusion: Aloe vera and CPP-ACFP produced synergistic effect for enhancing dentin remineralization in erosive lesions.
\end{abstract}

\section{INTRODUCTION}

Dental erosion is known as loss of dental hard tissue caused by acids, without involvement of bacteria. Human dentin has different types of Matrix metalloproteinases (MMPs), including MMPs 2, 3, 8, 9

- Paper extracted from Master thesis titled "Effect of Different Anticollagenolytic Agents on Dentin Erosion Before and After Casein Phospho Peptides-Amorphous Calcium Fluoride Phosphate Application"

1. Teacher assistant in Conservative Dentistry Department, Faculty of Oral and Dental Medicine, Future University in Egypt, Cairo, Egypt.

2. Professor of Operative Dentistry, Operative Dentistry Department, Faculty of Dental Medicine for Girls, Al-Azhar University, Cairo, Egypt.

3. Professor of Operative Dentistry, Operative Dentistry Department, Faculty of Dentistry, Cairo University, Cairo, Egypt.

4. Lecturer of Conservative Dentistry Department, Faculty of Oral and Dental Medicine, Future University in Egypt, Cairo, Egypt.

* Corresponding author email: drnourmoustafa@gmail.com 
and $20^{(1)}$. MMPs are known to play a key role in dentin organic matrix destruction following demineralization $^{(2)}$. Therefore (MMP) inhibition can reduce dentin organic part destruction ${ }^{(3)}$.

Chlorhexidine ( $\mathrm{CHX})$ is considered as the most famous endogenous dentine enzyme inhibitor. It has an inhibitory effect on the MMPs (against MMPs 2, 8 and 9) in the dentin ${ }^{(4,5)}$. In recent years, the potential for the inhibition of MMPs by substances derived from natural products has gained increasing attention. Among the numerous plants with therapeutic potential, Aloe vera is considered as a miracle plant due to its magical healing property in various human diseases. Aloesin, aloin and aloe-emodin are the most important metabolites in Aloe vera gel which exhibits MMP inhibitory effect against MMP 2 and $9^{(6)}$.

Several approaches studied dentin remineralization, using fluoride and amorpous calcium phosphate $^{(7)}$. Combination of Amorphous Calcium Fluoride Phosphate (ACFP) and Casein Phospho Peptides (CPP) which form a complex (CPP-ACFP) has been suggested to be effective in calcium and phosphate ions precipitation and in teeth remineralization ${ }^{(8)}$.

\section{MATERIALS AND METHODS}

\section{Teeth selection and preparation:}

For this study, 40 freshly extracted sound human maxillary first premolars were divided into two equal groups (20 premolars each) according to immersion in the tested anticollagenolytic agent $A$ : group $\left(A_{1}\right)$ Aloe vera and group $\left(A_{2}\right)$ Chlorhexidine. Each group was later subdivided into two equal subgroups (10 premolars each) according to microhardness measurement group $\mathrm{B}_{1}$ : before CPPACFP application and group $\mathrm{B}_{2}$ : after CPP-ACFP application.

\section{Specimen preparation:}

The teeth were sectioned longitudinally, by low speed saw cutting; ISOMET 4000 (Buehler Ltd.,
Lake Bluff, IL, USA) to expose the dentin of the buccal aspect of the tooth. The specimens including the roots were embedded in auto polymerizing acrylic resin.

A carbon pencil was used to mark a horizontal small window on the cervical coronal part of each specimen. Each specimen was coated with two layers of dark color acid resistant nail varnish except for the exposed window $(3 \times 3 \mathrm{~mm})$ for application of tested materials ${ }^{(9-1)}$. Baseline surface microhardness of the dentine specimen was recorded by using Vicker's microhardness tester ${ }^{(12,13)}$.

\section{Erosive lesions preparation:}

For erosive demineralization, the prepared teeth specimens were immersed in a glass container filled with $250 \mathrm{ml}$ of Coca-cola ${ }^{\circledR}$ (The Coca-Cola Company, Cairo - Egypt) at room temperature for 25 hs and the solution was changed each 5 hs. This protocol permits for observing the demineralization in a suitable time period ${ }^{(14,15)}$. Then the teeth were rinsed with de-ionized water ( $\mathrm{pH}$ 6.0), dried in open air and the surface microhardness of the dentine specimens was recorded again using Vicker's microhardness tester.

\section{MATERIALS PREPARATION}

\section{(a) Aloe vera:}

The Aloe vera solution was prepared by dissolving 2 gm of Aloe vera powder (Procured From Indigo Herbs Ltd Products, Wells Rd, UK) of 99\% purity A. Barbadensis Miller measured by analytical balance in $100 \mathrm{ml}$ of deionized water ${ }^{(16)}$.

\section{(b) Chlorohexidine:}

$100 \mathrm{ml}$ of $0.12 \%$ chlorhexidine hydrochloride, pH 6.0 (Hexitol mouth rinse, ADCO The Arab Drug Company, Cairo- Egypt LOT:21918) was used without dilution. 


\section{Specimens treatment protocol:}

The specimens were randomly assigned to two equal groups (20 premolars each) as follows $\left(\mathrm{A}_{1}\right)$ : Aloe vera $\left(\mathrm{A}_{2}\right)$ : Chlorhexidine. Dentine specimens in each group had been soaked in a glass container filled with $100 \mathrm{ml}$ of each testing solutions under constant agitation at room temperature ${ }^{(10,17)}$ for one minute ${ }^{(12,18)}$. The specimens were rinsed and kept in de-ionized water at $37^{\circ} \mathrm{C}$ for next day. This procedure was repeated daily for 7 days ${ }^{(19)}$.

At the end of all experimental days, each main group was further subdivided into two subgroups B (10 each) according to the application of CPPACFP application either before (group $\mathrm{B}_{1}$ ) or after CPP-ACFP application (group $\mathrm{B}_{2}$ ). CPP-ACFP (RECALDENTTM Tooth GC MI paste plus) was applied onto the exposed window of each specimen with micro-brush to just cover the dentin surfaces without brushing and left in place for $3 \mathrm{~min}$ utes following the manufacturer's instructions ${ }^{(20)}$. Thereafter, the CPP-ACFP paste was removed by rinsing the dentin surface with deionized water. Microhardness measurements were reassessed again after immersion and CPP-ACFP application.

\section{Micro-hardness assessment:}

The microhardness was measured onto dentin surface specimens four times, at baseline time, after the artificial erosion, after immersion in the treatment solutions and after CPP-ACFP application. Surface microhardness was recorded by using Vicker's microhardness tester with a 25gm load applied for five seconds. Vickers Hardness Number (VHN) of three indentations apart from each other by 100 microns were recorded and the average mean values were evaluated for each specimen ${ }^{(21)}$.

\section{Statistical analysis:}

Numerical data were investigated for normality by checking the distribution of data and utilizing tests of normality (Kolmogorov-Smirnov and Shapiro-Wilk tests). Microhardness data showed parametric distribution. Data had been presented as mean and standard deviation (SD) values. Repeated measures ANOVA test had been used to study the effect of material type, AFCP application and time of measurement on microhardness. The significance level had been set at $\mathrm{P} \leq 0.05$.

\section{RESULTS}

\section{a. Comparison between microhardness mean values of the two tested materials (Aloe vera and $\mathrm{CHX):}$}

The data in table (1) figure (1) shows the mean, standard deviation (SD) values and results of repeated measures ANOVA test for comparison of dentin microhardness of the two tested materials at different measurement times (base line, after erosion and after immersion in the tested material) with and without CPP-ACFP application. It was revealed the following:

Without AFCP application; there was no statistically significant difference between the two materials at base line as well as after erosion at ( $P$-value $=0.998$, Effect size $=0.0001)$ and at $(P$-value $=$ 0.946 , Effect size $=0.002$ ), respectively. However, after immersion there was no statistically significant difference between the two materials at ( $P$-value $=$ 0.734, Effect size $=0.012$ ).

With AFCP application; there was also no statistically significant difference between the two materials at base line as well as after erosion at $(P$-value $=0.966$, Effect size $=0.001)$ and at $(P$-value $=0.969$, Effect size $=0.001)$, respectively. However, after immersion there was no statistically significant difference between the two materials at $(P$-value $=0.844$, Effect size $=0.023)$. 
Table (1): The mean, standard deviation (SD) values and results of comparison between dentin microhardness values of the two tested materials with and without CPP-ACFP application at different measurement times.

\begin{tabular}{|c|c|c|c|c|c|c|}
\hline \multirow{2}{*}{ AFCP APPLICATION } & \multirow{2}{*}{ TIME } & \multicolumn{2}{|c|}{ ALOE-VERA } & \multicolumn{2}{c|}{ CHX } & \multirow{2}{*}{ P-VALUE } \\
\cline { 2 - 7 } & & Mean & SD & Mean & \multicolumn{2}{c|}{ SD } \\
\hline \multirow{3}{*}{ No AFCP } & Base line & 70.2 & 7.6 & 70 & 7.5 & 0.998 \\
\cline { 2 - 7 } & After erosion & 34 & 6.6 & 34.7 & 6 & 0.946 \\
\cline { 2 - 7 } & After immersion & $51.4^{\mathrm{A}}$ & 5.8 & $50.3^{\mathrm{A}}$ & 5.5 & 0.734 \\
\hline \multirow{2}{*}{ AFCP } & Base line & 69.5 & 6.2 & 69.5 & 7.3 & 0.966 \\
\cline { 2 - 7 } & After erosion & 34.9 & 5.8 & 34.5 & 6.4 & 0.969 \\
\cline { 2 - 7 } & After immersion & $58.8^{\mathrm{A}}$ & 6.6 & $56.5^{\mathrm{A}}$ & 3.8 & 0.844 \\
\hline
\end{tabular}

*: Significant at $P \leq 0.05$, Different superscripts in the same row are statistically significantly different.

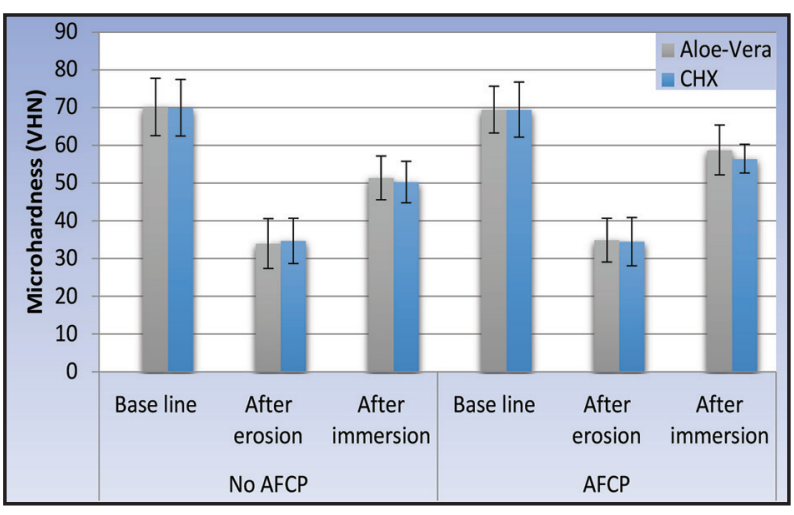

Figure (1): Bar chart representing the mean, standard deviation (SD) values and results of comparison between dentin microhardness values of the three tested materials with and without CPP-ACFP application at different measurement times.

\section{b. Comparison between microhardness values without and with CPP-AFCP application:}

The data in table (2), figure (2) shows mean values and $(\mathrm{SD})$ values and results of repeated ANOVA test for comparison between microhardness values with and without CPP-ACFP for each tested material at different times of measurement. It was revealed that:
For the Aloe-Vera group: at base line as well as after erosion, there was no statistically significant difference between microhardness values without and with AFCP application at $(P$-value $=0.850$, Effect size $=0.001)$ and at $(P$-value $=0.744$, Effect size $=0.002)$, respectively. However, after immersion in the Aloe vera and application of CPP-AFCP there was a statistically significantly increase in mean microhardness values than aloe vera with no CPP-AFCP application at $(P$-value $=0.003$, Effect size $=0.152)$.

For the CHX group: at base line as well as after erosion, there was no statistically significant difference between microhardness without and with AFCP application at $(P$-value $=0.885$, Effect size $=0.0001)$ and at $(P$-value $=0.941$, Effect size $=$ $0.0001)$, respectively. However, after immersion in the CHX and application of CPP-AFCP there was a statistically significantly increase in mean microhardness values than $\mathrm{CHX}$ with no CPP-AFCP application at $(P$-value $=0.012$, Effect size $=0.112)$. 
Table (2): The mean, standard deviation (SD) values and results for every tested material for comparison between microhardness values without and with CPP-AFCP application at different times of measurements.

\begin{tabular}{|c|c|c|c|c|c|c|}
\hline \multirow{3}{*}{ MATERIL } & \multirow{2}{*}{ TIME } & \multicolumn{2}{|c|}{ NO AFCP } & \multicolumn{2}{c|}{ AFCP } & \multirow{2}{*}{ P-VALUE } \\
\cline { 2 - 7 } & & Mean & SD & Mean & SD \\
\hline \multirow{3}{*}{ Aloe-Vera } & Base line & 70.2 & 7.6 & 69.5 & 6.2 & 0.850 \\
\cline { 2 - 7 } & After erosion & 34 & 6.6 & 34.9 & 5.8 & 0.744 \\
\cline { 2 - 7 } & After immersion & 51.4 & 5.8 & 58.8 & 6.6 & $0.003 *$ \\
\hline \multirow{3}{*}{ CHX } & Base line & 70 & 7.5 & 69.5 & 7.3 & 0.885 \\
\cline { 2 - 7 } & After erosion & 34.7 & 6 & 34.5 & 6.4 & 0.941 \\
\cline { 2 - 7 } & After immersion & 50.3 & 5.5 & 56.5 & 3.8 & $0.012 *$ \\
\hline
\end{tabular}

*: Significant at $P \leq 0.05$

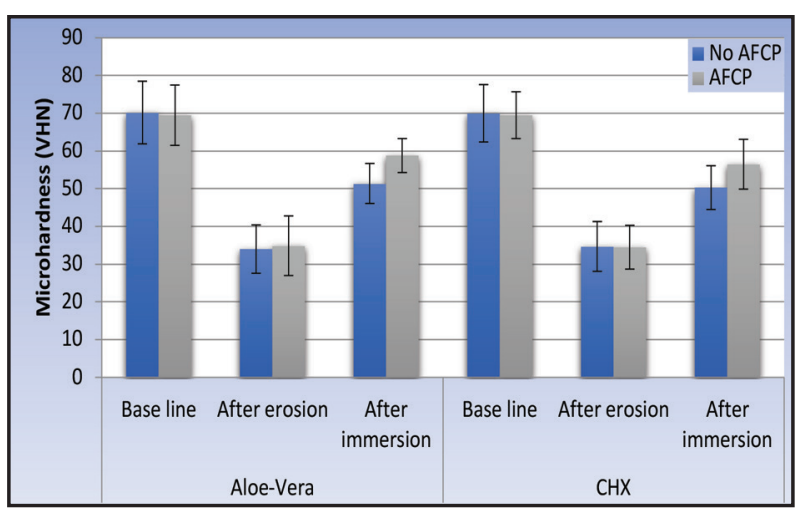

Figure (2): Bar chart representing mean and standard deviation values for every tested material for comparison between microhardness values without and with CPP$\mathrm{AFCP}$ application at different times of measurements.

\section{DISCUSSION}

Dentin erosion is a complicated process. It does not affect the surface only, in its sever cases it is accompanied by dentin exposure, which might be associated with painful hypersensitivity ${ }^{(22)}$. After mineral dissolution induced by acid, the organic matrix which primarily composed of collagen, is exposed $^{(18)}$. Distinctive types of MMPs had been recognized from human dentin, including MMPs $2,3,8,9,20$ which have a critical role in dentin collagen destruction, therefore, MMP inhibitors can prohibit or postpone erosion progression ${ }^{(5)}$.
The purpose of this study was to introduce new herbal product with possible potential for the inhibition of MMPs in order to stabilize dentin collagen and to evaluate the influence of Aloe vera on eroded dentin by measuring microhardness values in comparison to chlorohexidine. In this study, the Aloe vera was chosen as it is a globally popular natural product used locally in traditional medicine ${ }^{(23)}$.

Moreover, it has an inhibitory effect on the MMPs (against MMPs 2 and 9) in dentin ${ }^{(16)}$. This effect can be useful in preventing collagen degradation $^{(16)}$ and it was compared to chlorohexidine as the gold standard in chemical MMPs inhibitors.

Vickers microhardness test was chosen for this study since it is considered as a demonstrative factor for the mechanical dentin strength and it is generally a simple and reliable method. In addition, it is considered by many researches ${ }^{(13,18)}$. The results of this current study showed that there was no statistically significant difference between CHX and Aloe vera as both materials increased dentin microhardness values. The increase in VHN value observed with Aloe vera powder could be related to its main composition of flavonoid (anthocyanins) which is almost in agreement with a previous study ${ }^{(24)}$. Such an increase in dentin microhardness following immersion in Aloe vera goes in the same line with 
a study ${ }^{(16)}$ which evaluated the inhibitory impact of Aloe vera on MMP-2 and MMP-9 and proved that aloin is the active component in this plant.

The results revealed that $\mathrm{CHX}$ enhances dentin microhardness, and this is may be due to its strong inhibitory action on MMPs. This is in agreement with another study ${ }^{25)}$. The inhibitory impact of chlorhexidine on MMPs is related to it mechanism of chelation. It was similarly reported that chlorhexidine could affect cysteine and sulfhydryl groups in the active site of MMPs and the essential sulfhydryl groups $^{(25,26)}$. This results are supported by another study ${ }^{(5)}$ which stated that both CHX and Aloe vera have possible potential for erosion inhibition, due to their inhibition activity on MMPs. In the present study, we tried to stabilize the organic dentin matrix using the two tested materials and remineralize the inorganic part with CPP-ACFP. As minerals content and organic structure of dentin, both affect the dentin competence and control its functionality ${ }^{(27)}$. For this reason, functional remineralization was considered for the present study.

CPP-ACFP is a well-known dentin re-mineralizing agent, which enhances the remineralization of artificial caries more than when compared to CPP-ACP alone due to the presence of fluoride ions ${ }^{(28)}$. On comparing dentin microhardness values after tested materials immersion without and with CPP-AFCP application, it was noted that application of CPP-ACFP increased the microhardness values. This results agreed with a previous study ${ }^{(29)}$, which stated that MI Paste Plus is remineralizing agent based on the complex of casein phosphopeptide which stabilized amorphous calcium phosphate and could afford protection against erosion. This is due to the characteristic property of CPP in stabilizing and maintaining calcium and phosphate ions supersaturation with increased remineralization and decreased hydroxyapatite demineralization as justified by another research ${ }^{(30)}$. Also, another previous study ${ }^{(31)}$ reported that $\mathrm{CPP}-\mathrm{ACP}$ and fluoride combination showing higher remineralization potential on eroded lesions.

\section{CONCLUSIONS}

Under the limitations of this study, the followings could be concluded:

1. Both Aloe vera and chlorohexidine produced similar effect in enhancing dentin microhardness.

2. Chemical gold standard CHX could be substituted by natural safe herbal source and hence Aloe vera opens a new perspective for dental erosion protection.

3. Aloe vera and CPP-ACFP produced synergistic effect for enhancing remineralization in erosive lesions.

\section{REFERENCES}

1. Bourd-Boittin K, Fridman R, Fanchon S, Septier D, Goldberg M, Menashi S. Matrix metalloproteinase inhibition impairs the processing, formation and mineralization of dental tissues during mouse molar development. Exp Cell Res. 2005; 2:493-505.

2. Chaussain-Miller C, Fioretti F, Goldberg M, Menashi S. The role of matrix metalloproteinases (MMPs) in human caries. J Dent Res. 2006; 1:22-32.

3. Kato M.T, Leite A.L, Hannas A.R, Buzalaf M.R. Gels containing MMP inhibitors prevent dental erosion in situ. J Dent Res.2010; 5:468-72.

4. Tjäderhane L, Nascimento F.D, Breschi L, Mazzoni A, Tersariol I.L, Geraldeli S. Strategies to prevent hydrolytic degradation of the hybrid layer: A Review. Dent Materials. 2013; 10: 999-1011.

5. Sinha D.J, Jaiswal N, Vasudeva A, Garg P, Tyagi S.P, Chandra P. Comparative evaluation of the effect of chlorhexidine and Aloe barbadensis Miller (Aloe vera) on dentin stabilization using shear bond testing. JCD. 2016; 5: 406-10.

6. Rajasekaran S, Ravi K, Sivagnanam K, Subramanian S. Beneficial effects of Aloe vera leaf gel extract on lipid profile status in rats with streptozotocin diabetes. CEPP. 2006; 3:232-7.

7. Bertassoni L. E, Habelitz S, Marshall S. J, Marshall G.W. Mechanical recovery of dentin following remineralization in vitro-an indentation study. J Biomech. 2011; 1:176-81. 
8. Gurunathan D, Somasundaram S, Kumar S.A. Casein phosphopeptide-amorphous calcium phosphate: a remineralizing agent of enamel. ADJ. 2012; 4: 404-8.

9. Amaechi B.T, Higham S.M, Edgar W.M. Factors influencing the development of dental erosion in vitro: enamel type, temperature and exposure time. JDSOR. 1999; 8: 624-30.

10. Passos V.F, Melo M.A, Lima J.P. Active compounds and derivatives of camellia sinensis responding to erosive attacks on dentin. Braz oral Res. 2018; 1:100-40.

11. West N.X, Hughes J.A, Addy M. Erosion of dentine and enamel in vitro by dietary acids: the effect of temperature, acid character, concentration and exposure time. JDSOR.2000;10: 875-80

12. Barbosa C.S, Kato M.T, Buzalaf M.A. Effect of supplementation of soft drinks with green tea extract on their erosive potential against dentine. ADJ. 2011; 3: 317-21.

13. Jose P, Sanjeev K, Sekar M. Effect of green and white tea pretreatment on remineralization of demineralized dentin by CPP-ACFP-an invitro microhardness analysis. JCDR. 2016; 4:85- 9

14. Ehlen L.A, Marshall T.A, Qian F, Wefel J.S, Warren J. Acidic beverages increase the risk of in vitro tooth erosion. Nutr Res. 2008; 5: 299-303.

15. Touyz L, Nassani L.M. Acidity and Dental Erosion from Apple-and Grape-Juice (An in vitro and in vivo Report). Int J Oral Dent Health. 2018; 1:40-61.

16. Kudalkar M.D, Nayak A, Bhat K.S, Nayak R.N. Effect of Azadirachta indica (Neem) and Aloe vera as compared to subantimicrobial dose doxycycline on matrix metalloproteinases (MMP)-2 and MMP-9: An in-vitro study. Ayu. 2014; 1: 85-9.

17. De Moraes M, Carneiro J.R, Passos V.F, Santiago S.L. Effect of green tea as a protective measure against dental erosion in coronary dentine. Braz oral Res. 2016;1:1-13.

18. Mirkarimi M, Toomarian L. Effect of green tea extract on the treatment of dentin erosion: an in vitro study. Int. J. Dent. 2012; 4: 224-8

19. Abdulraheam A, Rukhosh H. Effect of Different Tea in Remineralization of Artificially-Induced Initial Enamel Caries of Human Teeth: An in vitro study. TJDS. 2011; 1:19-24.

20. Kumar V.L, Itthagarun A, King N.M. The effect of casein phosphopeptide-amorphous calcium phosphate on rem- ineralization of artificial caries-like lesions: An in vitro study. ADJ. 2008; 1: 34-40.

21. Jose P, Sanjeev KSekar M. Effect of green and white tea pretreatment on remineralization of demineralized dentin by CPP-ACFP-an invitro microhardness analysis. JCDR. 2016; 10: 85-92.

22. Kato M.T, Magalhães A.C, Rios D, Hannas A.R, Attin T. Protective effect of green tea on dentin erosion and abrasion. J. Appl. Oral Sci.2009; 6: 560-4.

23. Nithin V, Krishnan A.R, Raj S.V, Thomas D, Gopinathan P.A. "Aloevera" the herbal product in dentistry. President's Message. 2018; 2: 43-5.

24. Santos J, La V.D, Bergeron C, Grenier D. Inhibition of host-and bacteria-derived proteinases by natural anthocyanins. J. Periodontal Res. 2011; 5: 550-7.

25. Magalhães A.C, Wiegand A, Rios D, Hannas A, Attin T, Buzalaf M. Chlorhexidine and green tea extract reduce dentin erosion and abrasion in situ. Int. J. Dent. 2009; 12: 994-8.

26. Gendron R, Grenier D, Sorsa T, Mayrand D.D. Inhibition of the activities of matrix metalloproteinases 2, 8, and 9 by chlorhexidine. Clin. Diagn. Lab. Immunol., 1999. 3: 437-9.

27. Bertassoni L.E, Habelitz S, Kinney J. H, Marshall S.J. Biomechanical perspective on the remineralization of dentin. Caries Res ISSN. 2009;1:70-7.

28. Shen P, Manton D.J, Cochrane N.J, Walker G.D, Yuan Y, Reynolds C. Effect of added calcium phosphate on enamel remineralization by fluoride in a randomized controlled in situ trial. Int. J. Dent. 2011; 7: 518-25.

29. Poggio C, Gulino C, Mirando M, Colombo M, Pietrocola G. Preventive effects of different protective agents on dentin erosion: An in vitro investigation. J clin exp dent. 2017; 1: 7-12.

30. Agob J.N, Aref N.S, Al-Wakeel E. Effect of casein phosphopeptide-amorphous calcium phosphate on fluoride release and micro-shear bond strength of resin-modified glass ionomer cement in caries-affected dentin. Restor Dent Endod. 2018; 4: 45-56.

31. Srinivasan N, Kavitha M, Loganathan S. Comparison of the remineralization potential of $\mathrm{CPP}-\mathrm{ACP}$ and $\mathrm{CPP}-\mathrm{ACP}$ with 900 ppm fluoride on eroded human enamel: an in situ study. Arch. Oral Biol. 2010; 7: 541-4. 